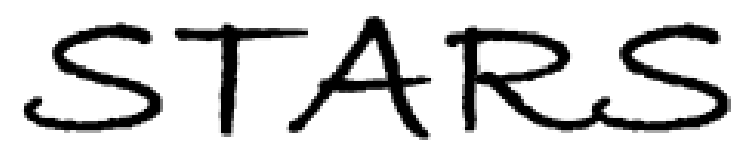

University of Central Florida

STARS

$1-1-2004$

\title{
Wavelength-insensitive all-optical clock extraction and enhancement of nonreturn-to-zero data using a semiconductor optical amplifier and fiber Bragg grating
}

\author{
Xiaoxu Li \\ Cheolhwan Kim \\ Guifang Li \\ University of Central Florida
}

Find similar works at: https://stars.library.ucf.edu/facultybib2000

University of Central Florida Libraries http://library.ucf.edu

This Editorial Material is brought to you for free and open access by the Faculty Bibliography at STARS. It has been accepted for inclusion in Faculty Bibliography 2000s by an authorized administrator of STARS. For more information, please contact STARS@ucf.edu.

\section{Recommended Citation}

$\mathrm{Li}$, Xiaoxu; Kim, Cheolhwan; and Li, Guifang, "Wavelength-insensitive all-optical clock extraction and enhancement of nonreturn-to-zero data using a semiconductor optical amplifier and fiber Bragg grating" (2004). Faculty Bibliography 2000s. 4543.

https://stars.library.ucf.edu/facultybib2000/4543

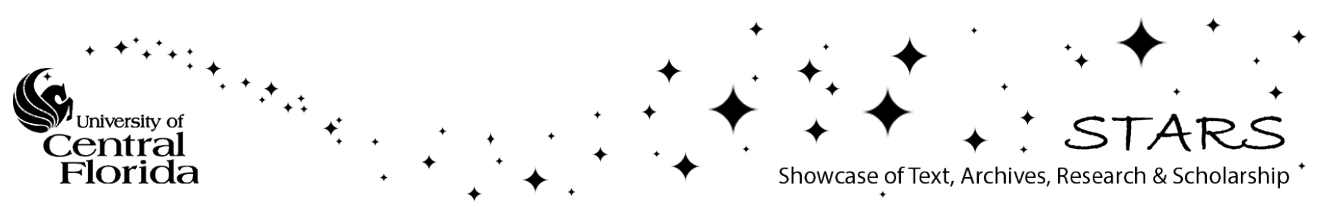


Wavelength-insensitive alloptical clock extraction and enhancement of nonreturn-to-zero data using a semiconductor optical amplifier and fiber Bragg grating

\author{
Xiaoxu Li \\ Cheolhwan Kim \\ Guifang Li, MEMBER SPIE \\ University of Central Florida \\ College of Optics \& Photonics \\ Florida Photonics Center of Excellence \\ Orlando, Florida 32816-2700 \\ E-mail: gli@mail.ucf.edu
}

$\mathbf{R}$

Abstract. A scheme for wavelength and polarization insensitive all-optical clock extraction and enhancement of nonreturn-to-zero (NRZ) data is proposed and demonstrated. At $10 \mathrm{Gbit} / \mathrm{s}$, more than 7-dB clock enhancement and 19-dB clock-to-data suppression ratio (CDSR) enhancement have been realized using a semiconductor optical amplifier (SOA) and a reflective fiber Bragg grating (FBG) over a 30-nm input wavelength range. (c) 2004 Society of Photo-Optical Instrumentation Engineers. [DOI: 10.1117/1.1789988]

Subject terms: semiconductor optical amplifier; fiber Bragg grating; all-optical clock extraction; nonreturn-to-zero.

Paper 04037 received Apr. 7, 2004; revised manuscript received Jun. 25, 2004; accepted for publication Jun. 17, 2004; appeared online Jun. 29, 2004.

\section{Introduction}

All-optical clock recovery is an important technology required for all-optical networking. It is more difficult to recover a clock signal from the nonreturn-to-zero (NRZ) format ${ }^{1,2}$ than the return-to-zero (RZ) format, ${ }^{3,4}$ since virtually no clock component exists in the NRZ modulation spectrum, therefore clock extraction and enhancement is required before the clock can be recovered. In Ref. 1, the input NRZ format was converted to a pseudo-RZ (PRZ) format using a semiconductor optical amplifier (SOA) and a narrowband grating filter. The self-phase modulation (SPM)-induced chirp component was extracted from the SOA-amplified signal, and the resultant PRZ stream has a peak at each leading edge of NRZ pulses. While in Ref. 2, a frequency modulation (FM) to amplitude modulation (AM) converter was employed after the SOA to split each self-phase modulated NRZ pulse into two, thereby clock enhancement was achieved. These approaches are, however, wavelength sensitive. They require the input NRZ signal to be at a fixed wavelength and are not flexible in practical systems. In this work, we demonstrate a wavelength and polarization insensitive scheme for clock extraction and enhancement from NRZ data using the combined effect of cross-gain modulation (XGM) and cross-phase modulation (XPM) in a SOA.

\section{Experimental Setup}

The experimental setup is shown in Fig. 1. The NRZ data was generated by externally modulating the continuouswave $(\mathrm{cw})$ tunable laser with a $2^{31}-1$ pseudorandom bit sequence (PRBS) from a pulse pattern generator. The input NRZ signal, acting as the pump, and a cw laser, acting as the probe, were combined through a 3-dB coupler and injected into a SOA for wavelength conversion. The polarization-insensitive SOA (Alcatel M1002) used in the experiment was biased at $120 \mathrm{~mA}$. A tunable filter with a bandwidth of $0.9 \mathrm{~nm}$ centered at the probe wavelength was used after the SOA to retain the probe signal and to reject the pump signal as well as amplified spontaneous emission (ASE) noise. The FM-to-AM converter consists of a circulator and a FBG, with its main lobe having a bandwidth of $1.37 \mathrm{~nm}$ and nearly $100 \%$ reflectivity. The total insertion loss induced by the circulator-FBG assembly was $4.5 \mathrm{~dB}$. The notch between the main lobe and the first sidelobe in the reflection spectrum of FBG acts as a 0.1-nm bandwidth notch filter. The probe wavelength was set close to the center wavelength of the notch filter.

\section{Results}

Figure 2(a) shows the waveform and chirp of the wavelength converted signal, which is inverted from the incoming NRZ data at $10 \mathrm{Gbit} / \mathrm{s}$ due to the XGM effect of the SOA. The probe power and input data power were 0.8 and $0.4 \mathrm{~mW}$, respectively. The leading edge and trailing edge of each inverted pulse were blue and red shifted, respectively, through the XPM effect of the SOA, which is consistent with the work in Ref. 5. After going through the notch filter, which is centered about the probe wavelength, the blue- and red-chirped components at the leading and trailing edges containing the clock passed through, while the unchirped component at the center of the pulses containing data was blocked. As a result, the data component was attenuated and two peaks were present in the pulses after the notch filter, which is shown as Fig. 2(b). Figure 2(c) shows the rf spectrum of the wavelength converted signal with an optical power of $0.84 \mathrm{~mW}$. A clock component of $-48.16 \mathrm{dBm}$ was obtained. After clock enhancement using the circulator and FBG, the average optical power of the signal was reduced to $0.24 \mathrm{~mW}$ due to the insertion loss of the circulator-FBG assembly. However, as shown in Fig. 2 (d), the clock component was enhanced to $-40.83 \mathrm{dBm}$ and the CDSR was enhanced by $19.16 \mathrm{~dB}$. Excluding the insertion loss, the clock enhancement would be $16.33 \mathrm{~dB}$. When the probe power is set as $-1 \mathrm{dBm}(0.8 \mathrm{~mW})$, clock enhancement operates over a large range of input data

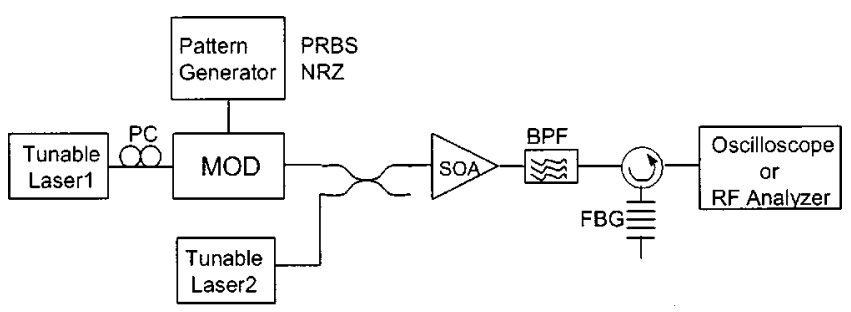

Fig. 1 Experimental setup. PC: polarization controller. MOD: modulator. 


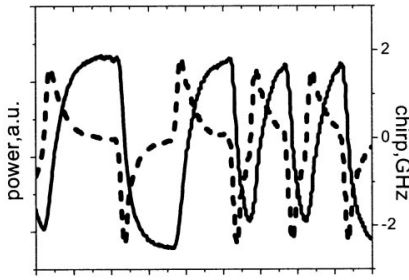

time,100ps/div

a

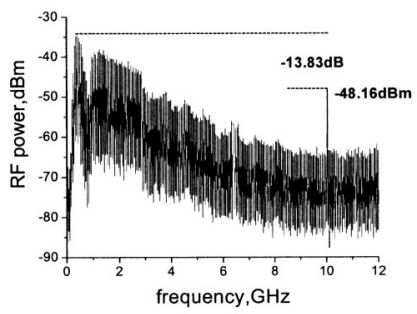

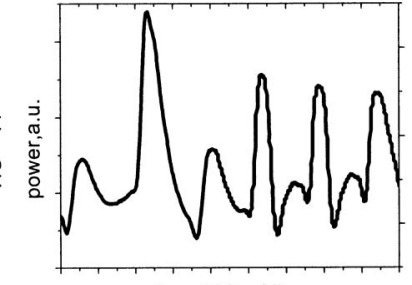

time, $100 \mathrm{ps} / \mathrm{div}$

$\mathrm{b}$

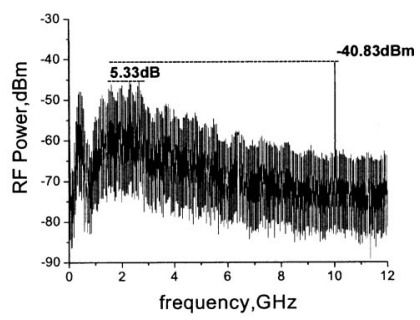

d
Fig. 2 (a) Waveform(solid) and chirp(dot) of signal before enhancement. (b) Waveform of signal after enhancement. (c) The rf spectrum of the signal before enhancement. (d) The rf spectrum of the signal after enhancement.

power; the 3-dB dynamic range of input power from $-11 \mathrm{dBm}(80 \mu \mathrm{W})$ to $3 \mathrm{dBm}(2 \mathrm{~mW})$ was achieved.

The clock enhancement requires that the detuning between the optical frequency of the probe and the center frequency of the narrowband notch filter be kept in a small range. It was observed that the optimal probe frequency range was from -0.4 to $+0.2 \mathrm{GHz}$ with respect to the center frequency of the notch filter. Within this range, clock enhancement was almost constant. While out of this range, clock enhancement decreased quickly. After the probe wavelength was optimized, clock enhancement was maintained at around $16 \mathrm{~dB}$ (excluding the insertion loss) over a large range of input wavelength (1530 to $1545 \mathrm{~nm}$, and 1550 to $1565 \mathrm{~nm}$ ), as shown in Fig. 3. The enhancement dropped quickly when the input wavelength was close to the probe wavelength, because of the low wavelength conversion efficiency and limited bandwidth of the tunable filter. Figure 4 presents the measured clock enhancement (excluding insertion loss) and CDSR enhancement as

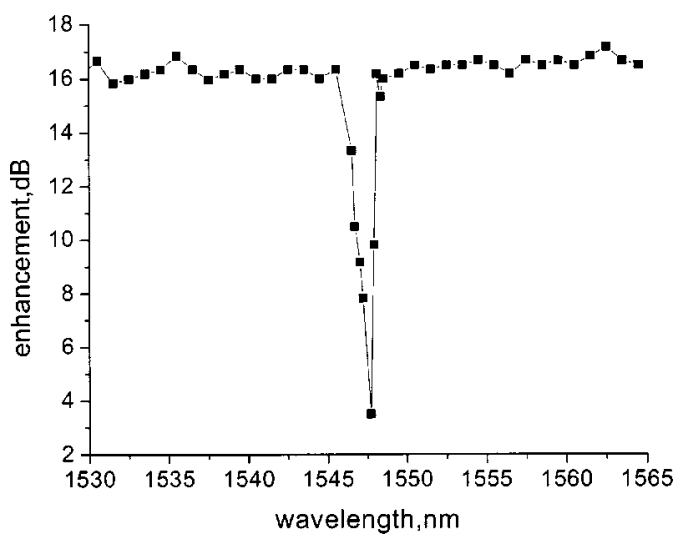

Fig. 3 Clock enhancement (excluding insertion loss) of $10 \mathrm{Gbit} / \mathrm{s}$ NRZ data as a function of the input wavelength.

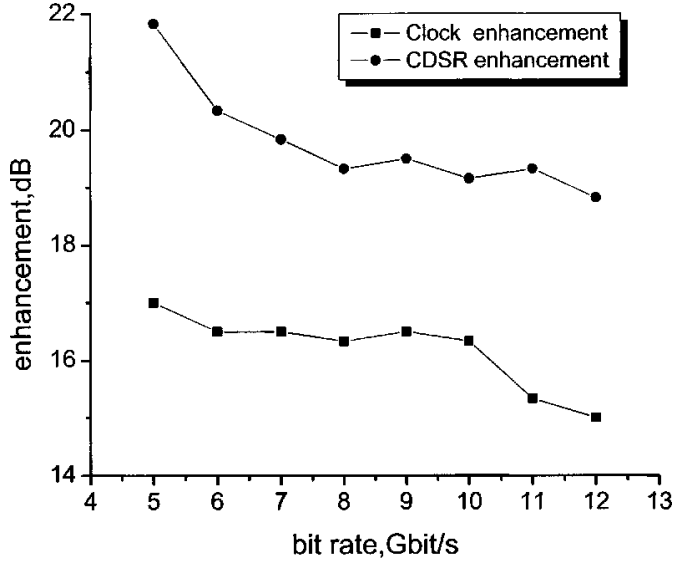

E

Fig. 4 Enhancements as functions of the bit rate.

functions of the bit rate of the NRZ data up to $12 \mathrm{Gbit} / \mathrm{s}$, which is the limit of the bit error rate tester used in the experiment.

\section{Conclusion and Discussion}

Wavelength and polarization insensitive clock enhancement and CDSR enhancement of NRZ data are experimentally demonstrated over a large input wavelength range $(30 \mathrm{~nm})$. Measured clock enhancement is more than $14 \mathrm{~dB}$, excluding insertion losses due to the circulator and the reflective FBG used in the experiment. The clock-enhancement scheme can be improved by using a transmission-type FBG, which we did not have at the time of the experiment (but is commercially available), to avoid these insertion losses. A 14-dB dynamic range of the clock enhancement scheme is demonstrated in the experiment. This dynamic range can be improved further by using higher probe powers at the expense of reduced peak clock enhancement. At higher bit rates over $10 \mathrm{Gbit} / \mathrm{s}$, the performance is limited by the carrier recovery time of the SOA used in the experiment, and can be improved by using SOAs with ultrafast carrier dynamics by increasing the bias current, optical input power, confinement factor, and differential gain. ${ }^{5}$ Such SOAs have been used for XGM and XPM wavelength conversion at data rates up to $160 \mathrm{Gbit} / \mathrm{s}^{6}$

\section{Acknowledgment}

This work has been supported in part by NSF under grant numbers $0114418,9980316,9976513$, and 0327276.

\section{References}

1. H. J. Lee, H. G. Kim, J. Y. Choi, and H. K. Lee "All-optical clock recovery from NRZ data with simple NRZ-to-PRZ converter based on self-phase modulation of semiconductor optical amplifier," Electron. Lett. 35(12), 989-990 (1999).

2. W. Mao, M. Al-Mumin, X. Wang, and G. Li "All-optical enhancement of clock and clock-to-data ratio suppression ratio of NRZ data," IEEE Photonics Technol. Lett. 13(3), 239-241 (2001).

3. B. Sartorius, C. Bornholdt, O. Brox, H. J. Ehrke, D. Hoffman, R. Ludwig, and M. Möhrle "All-optical clock recovery module based on self-pulsating DFB laser," Electron. Lett. 34(17), 1664-1665 (1998).

4. W. Mao, Y. Li, M. Al-Mumin, and G. Li "All-optical clock recovery from RZ-format data by using a two-section gain-coupled DFB laser," J. Lightwave Technol. 20(9), 1705-1714 (2002).

5. T. Durhuus, B. Mikkelsen, C. Joergensen, S. L. Danielson, and K. E. Stubkjaer "All-optical wavelength conversion by semiconductor optical amplifiers," J. Lightwave Technol. 14(6), 942-954 (1996).

6. C. Schubert, S. Diez, J. Berger, R. Ludwig, U. Feiste, H. s. Weber, G. Toptchiyski, K. Petermann, and V. Krajinovic "160-Gbit/s all-optical demultiplexing using a gain-transparent ultrafast-nonlinear interferometer (GT-Uni)," IEEE Photonics Technol. Lett. 13(5), 475-477 (2001) 